\title{
Moral, representación y "feminismo mapuche": elementos para formular una pregunta
}

\author{
Antonieta Vera Gajardo \\ Centro de Investigaciones Socioculturales (CISOC), Universidad Alberto Hurtado. \\ Santiago, Chile. \\ Email: mverag@uahurtado.cl
}

\begin{abstract}
Resumen: ${ }^{1}$ Este trabajo se pregunta por las posibles dificultades para la emergencia de un "feminismo mapuche" organizado en Chile. Para ello, se sugieren algunas afinidades entre las declaraciones públicas de algunas mujeres Mapuche contemporáneas y las paradojas a las que las feministas afroamericanas, chicanas y musulmanas han debido hacer frente en diferentes contextos de dominación. La hipótesis del texto es que la representación del feminismo "separatista”, la culpabilización al denunciar la violencia vivida al interior de sus comunidades, la ansiedad de los nacionalismos desvirilizados, la invisibilización por parte de los feminismos "blancos" y el llamado a representar la dignidad de un pueblo, son algunas de las contradicciones que estas mujeres comparten en el proceso de construcción de una subjetividad política feminista.
\end{abstract}

Palabras clave: mujeres Mapuche, feminismo, moral, colonialismo.

\section{Moral, representation and "Mapuche feminism": elements to formulate a question}

\begin{abstract}
This work wonders about the possible difficulties for the emergence of an organized "Mapuche feminism" in Chile. To do this, some affinities between the public statements of some contemporary Mapuche women and the paradoxes that Afro-American, Chicanas and Muslim feminists have faced in different contexts of domination are suggested. The hypothesis of the text is that the representation of "separatist" feminism, the blaming when denouncing violence experienced within their communities, the anxiety of devirilized nationalisms, the invisibilization on the part of "white" feminisms and the call to represent the dignity of a people, are some of the contradictions that these women share in the process of building a feminist political subjectivity.
\end{abstract}

Key words: Mapuche women, feminism, moral, colonialism.

\section{Moral, representação e “feminismo Mapuche”: elementos para formular uma pergunta}

Resumo: Este artigo pergunta sobre as possíveis dificuldades para o surgimento de um "feminismo Mapuche", organizado no Chile. Para isso, são sugeridas algumas afinidades entre as declarações públicas de algumas mulheres Mapuche contemporâneas e os paradoxos que as feministas afro-americanas, chicanas 
e muçulmanas têm enfrentado em diferentes contextos de dominação. A hipótese do texto é que a representação do feminismo “separatista”, o sentimento de culpa ao denunciar a violência experimentada dentro de suas comunidades, a ansiedade dos nacionalismos desvirilizados, a invisibilidade por parte dos feminismos "brancos" e o chamado para representar a dignidade de um povo, são algumas das contradições que essas mulheres compartilham no processo de construção de uma subjetividade política feminista.

Palavras-chave: mulheres Mapuche, feminismo, moral, colonialismo.

“Todas las lenguas se besan en mí soy entonces la boca

que se abre al resplandor $(\ldots)$

Abuelo mío expulsado -te canto y te redimo-

Ah, los machos del templo sacudiendo el vaticinio amargo de los siglos (...)

Malleus Maleficarum abuela mía Cornelio Saavedra y el hijo de puta que lo parió (...)

Hija mía que tiembla el cetro de las sucesiones Abuelo mío delirante en alcohol manso te canto y te redimo”

Adriana Paredes Pinda "Parias"

Itinerario de una pregunta

En los últimos años, mi trabajo se ha abocado a estudiar lo que he llamado “el discurso de la superioridad moral de las mujeres”, haciendo referencia a una serie de retóricas según las cuales existiría un conjunto de cualidades “específicamente femeninas” como la proximidad, la fuerza, el cuidado de la vida, la capacidad de mediación, la madurez, etc. que vendrían a humanizar, renovar y limpiar la política.

Pensando en la cuestión de los valores que sostienen las normas de 
“la mujer legítima” en el Chile contemporáneo, mis primeros trabajos sobre este tema se consagraron al estudio de los usos conservadores y progresistas del discurso de "la superioridad moral de las mujeres" en el país. Entre estos últimos, analicé el discurso de género de la primera campaña presidencial de Michelle Bachelet y los argumentos de algunas de las feministas que sostuvieron esa campaña. Así, me encontraba -por ejemplo- con las palabras de Pía Barros:

"Si se pudiera hablar con la futura presidenta, enviarle una carta (...) Yo le pediría un país como una casa (...) Michelle Bachelet encarna la persona que yo quisiera ser (...) aquella que sabe ponerse en el lugar del otro, que es capaz de renacer de sus cenizas (...) Ella es una heroína capaz de mirar su dolor solamente para crecer y no para odiar” (Barros, 2006, párr.1-2, énfasis mío).

Patricia Crispi, a su vez, remarcaba:

"Michelle- antes que todo- es eso: una sonrisa que expresa la reconciliación personal profunda, sonrisa que simboliza y que es el espejo de nuestra posibilidad de reconciliación nacional (...) Michelle es la "bella" que en nuestro sueño domesticará a la "bestia” $(. .$.$) todo será posible para "el segundo sexo" (...) Inaugurare-$ mos una nueva manera de hacer política (...) Tendremos, además de la testosterona, la cuota de progesterona de la cual nuestra sociedad tiene necesidad” (Crispi, 2006, párr.1-3, énfasis mío).

En un escenario previamente dispuesto por campañas como las del SERNAM en el 2003 -“Chile necesita fuerza de mujer”- (Vera, 2009), Michelle Bachelet se presentaba en la franja de la segunda vuelta con Sebastián Piñera el 2006, afirmando: "Quiero dirigirme a aquellos que no votaron por mí porque soy mujer...Cada familia es un reino, donde el padre reina pero la madre gobierna (...) Traigo un liderazgo diferente, con la sensibilidad de quien mira las cosas desde otro ángulo" (citada en Vera, 2009: 123).

A partir de esos primeros trabajos, pude concluir que en un contexto global de crisis de la representatividad política y en un contexto local insistentemente postdictatorial (en el que las irrupciones de la memoria (Wilde, 1999) y los rituales de refundación y unidad nacional no dejaron de proliferar), "la política de la proximidad” y el discurso pragmático de Bachelet sobre el "liderazgo femenino diferente", le permitieron ofrecer de manera exitosa su "buena femineidad nacional" en tanto "maternidad pública” y encarnación de la reconciliación nacional (Vera, 2009).

Fue después de buscar, a fines del siglo XIX y comienzos del siglo $\mathrm{XX}$, la genealogía de este discurso de "la femineidad" que la presenta como patrimonio y recurso en la arena política (Vera, 2012), que las palabras de Juana Calfunao me estimularon a pensar en la evidente "blanquitud" ${ }^{2}$ del feminismo institucional en Chile. Junto con lo anterior, comencé a reflexio- 
nar en algunas afinidades entre la representación corporal de "la mujer mapuche” y otros cuerpos de mujeres racializadas a las cuales históricamente se les ha encomendado encarnar la tradición de sus pueblos.

El carácter del presente trabajo es preliminar y corresponde a un ensayo reflexivo que podría ser el punto de partida para una investigación de más largo aliento. Así, he construido un corpus acotado que incluye declaraciones públicas de dirigentas mapuche, documentos emanados de la web, prensa, textos escritos por ensayistas o investigadoras mapuche y fragmentos de entrevistas realizadas a mujeres mapuche en los últimos años. La metodología del texto consistirá en analizar estas voces en primera persona desde los feminismos “de color" y la teoría feminista post/de/ anticolonial, con el objetivo de construir relaciones entre ellos y, simultáneamente, entre éstos y los testimonios de mujeres cuyas experiencias en otras épocas y contextos de acoso racista, sugiero afines. De esta manera, construiré algunos ejemplos de un fenómeno aún poco estudiado en nuestro país: el mutuo modelamiento de racismo y sexismo en el contexto reivindicativo mapuche contemporáneo. Finalmente y a partir de este análisis, pretendo sustentar la validez de una pregunta sobre las posibilidades y obstáculos para la emergencia de un "feminismo mapuche” en Chile.

\section{Interpelaciones mapuche al feminismo "blanco" en Chile}

En el 2011, coincidiendo en el mismo lugar físico con la ex-presidenta de Chile y en ese momento directora de ONU-MUJER, Michelle Bachelet, Calfunao junto a otros mapuche extendieron un lienzo: “¡ONU-MUJERES, Bachelet Genocida Fuera!”. En el comunicado publicado en su blog, la longko explica:

"Nosotros los pueblos y mujeres indígenas solicitamos encarecidamente que la ex-mandataria Bachelet, debe renunciar al cargo ante Naciones Unidas, porque no cuenta con la ética propia de una defensora de los derechos de la mujer (...) Una mujer con las manos manchadas con sangre, no debe dirigir el destino y los derechos de las mujeres del mundo” (Calfunao, 2011, párr. 4-7, énfasis mío).

Afines a estas palabras me parecieron las declaraciones de la "Red de Mujeres Mapuche”, coordinada por Diva Millapan:

"La mujer mapuche sigue viviendo una triple discriminación. Discriminación de género, por ser indígena y por estar en situación de pobreza (...) Nos llama la atención el silencio del Servicio Nacional de la Mujer (SERNAM) (...) Recordamos que es deber constitucional de Sernam velar por la integridad de todas las mujeres de este territorio...” (Red de mujeres mapuche, 2013, párr. 1 y 4, énfasis mío).

En un documento escrito un año antes, Millapan reflexionaba: "Entiendo que los cupos para las mujeres son escasos y ellas no los van a 
compartir con las mujeres representantes de los pueblos indígenas, eso es el fondo del problema” (Millapan, 2012, párr. 17, énfasis mío).

En la misma línea, una mujer mapuche anónima entrevistada por Charlotte Mattus, señala:

"Ha sido bastante duro...con mujeres que no son indígenas que quieren que uno se someta a los cánones que ellas tienen (...) Te miran de repente como estas pobrecitas indígenas que hay que ayudar (...) No te ven como distinto y como que uno puede aportar..." (2009:21).

La lucidez que tienen en común las palabras de estas mujeres, emerge desde la memoria nunca apaciguada del colonialismo. En ellas se devela la norma racializada de la femineidad (Dorlin, 2005), a partir de la cual ciertas mujeres en Chile serán más “verdaderas” y otras más “irreales”.

El feminismo "negro” ha demostrado esto último con maestría, interpelando sistemáticamente al sujeto de la unidad política del feminismo: "Nosotras, las mujeres” (Dorlin, 2005:83) ${ }^{3}$.

Haciendo hablar al pasado esclavista, las feministas “negras” de los años setenta en Estados Unidos, reivindicaron las palabras de mujeres como Sojourner Truth, quien en 1851 “exhibía ante un público abolicionista el espectáculo de sus brazos desnudos y musculosos de antigua esclava, para contrariar la imagen estereotipada de la fragilidad femenina” (Varikas, 2006: 126). En esa ocasión, Truth decía:

"Ese hombre de allí dice que las mujeres necesitan ayuda para subirse a los carruajes, para cruzar las zanjas y que ellas deben tener el mejor sitio en todas partes. ¡Pero a mí nadie me ayuda a subir a los carruajes, ni a pasar sobre los charcos, ni me dejan un sitio mejor! ¿Y acaso no soy una mujer? ¡Miradme! ¡Mirad mis brazos! He arado, plantado y cosechado, y ningún hombre podía superarme. ¿Y acaso no soy una mujer?” (Truth, 1851, párr. 2).

Angela Davis (2004) se encargará justamente de historizar el racismo que desde la época abolicionista y sufragista, marcó el feminismo en Estados Unidos. Así por ejemplo, se referirá a la feminista Elizabeth Stanton, quien en los años 1860s remarcaba de manera vehemente la necesaria y legítima prioridad de las mujeres y esposas "blancas” por sobre los "negros" (y en consecuencia, por sobre "las negras") a la hora de hablar sobre el derecho al voto. A través de esta reivindicación perversa, señala Elsa Dorlin, las "blancas” simplemente excluyen a las "negras” de la categoría "mujeres":

“Las esposas modelo de la clase dirigente encarnan el sujeto del feminismo, esa mujer de reputación dulce, moralmente irreprochable, piadosa, sensible, púdica y maternal. Comprendemos entonces, cómo 
la categoría política “mujeres” -dicho de otra manera, el sujeto político del feminismo-, implosiona -literalmente- bajo el efecto del racismo de ciertas militantes feministas. Considerando que las mujeres serían prioritarias en relación a los Negros, se supone que todas las mujeres son blancas y que todos los Negros son hombres” (2005: 86) $)^{4}$.

Es a partir de este tipo de hechos que Adrienne Rich hablará del “solipsismo blanco” del feminismo: aquella comprensión de la dominación que toma la situación de las mujeres "blancas" como "la situación de todas las mujeres, la modalidad universal de la dominación de género” (citada en Dorlin, 2005: 88). Se evidencia a través de ello, la jerarquía entre "las voces altas” de las mujeres "blancas” que han negociado su rol subordinado en el orden de género y "las voces bajas" de las mujeres empobrecidas y racializadas por el mismo orden (Bidaseca, 2010; 2011).

Así, interpelando a Bachelet, Juana Calfunao desmiente con claridad rotunda el "liderazgo femenino diferente" encarnado por la primera presidenta de Chile. Interpelando al SERNAM, la Red de Mujeres Mapuche evoca una pregunta inquietante, enunciada hace más de siglo y medio: “ ¿Y acaso no soy una mujer?”.

\section{Representar la raza}

Una experiencia de irrealidad afín a la señalada, fue probablemente la que experimentaron algunas de las mujeres afroamericanas sobre las que trabajó Kimberle Crenshaw durante los años ochenta. Golpeadas por sus maridos y en contradicción ante la posibilidad de denunciar, estas mujeres fueron acusadas de sumisas por las feministas y de separatistas por los líderes del movimiento antiracista, que vieron en sus denuncias, una traición que reforzaría el estereotipo del “negro violento”. Frente a las feministas, los argumentos de varias de estas mujeres afroamericanas eran claros: las mujeres "blancas" afirmaban que el mundo estaba hecho a imagen y semejanza de los hombres...pero sus propias experiencias les decían que el mundo no estaba hecho a la medida de los hombres "negros”. Además, las "blancas” no necesitaban negociar con la culpa instalada por el llamado a la lealtad de parte de sus comunidades. Y finalmente, ¿por qué confiar en la policía? (Crenshaw, 2005).

\section{Al respecto, Crenshaw sostiene:}

"Los hombres de color y las mujeres blancas son raramente confrontados a esta dimensión interseccional particular de la desposesión que obliga al individuo a separar su energía política entre dos proyectos a veces antagonistas (...) El racismo, tal como es vivido por las personas de color de un sexo en particular (masculino) determina ampliamente los parámetros de las estrategias antirracistas, de la misma manera que el sexismo tal como es vivido por mujeres de una 
raza particular (blanca) se encuentra ampliamente en la base del movimiento de mujeres” (2005:61).

Efectivamente, presentadas las identidades “mujer” y “persona de color" como posiciones excluyentes, se relega a las mujeres "de color” a “un lugar difícilmente accesible al lenguaje” (2005:53, énfasis mío).

Un clivaje similar es relatado por Mary Louise Pratt (1993) con respecto al movimiento chicano, que -inspirado en gran medida por el "Black Power"5-, se consolida como proyecto nacionalista en la frontera norte de México (Texas, Nuevo México, Colorado, California) durante los años sesenta. Pratt relata que, en esos años, era común que si una mujer tenía por pareja a un "anglo", si dejaba su comunidad de origen en la búsqueda de estudios universitarios o si se volvía feminista, fuera tratada de "Malinche" al interior del movimiento. Es a partir de esas experiencias y en respuesta al Plan de Aztlán, denunciado como manifiesto nacionalista androcéntrico, que las mujeres chicanas divulgarán en 1971 un documento propio, Chicanas Speak Out, y crearán una serie de resignificaciones políticas del estrecho binomio Malinche-Guadalupe ${ }^{6}$.

Este lugar difícilmente inteligible al que los feminismos "blancos” y las comunidades acosadas por el racismo parecen confrontar a las mujeres “de color”, también es identificable en los debates contemporáneos acerca de "la cuestión del velo" en Francia”.

Houria Boutelja, portavoz del movimiento Les Indigènes de la République $^{8}$, ha criticado en numerosas ocasiones el pretendido "universalismo” del feminismo en Francia. Así por ejemplo, Boutelja nos cuenta de una marcha realizada el 8 de marzo del 2007, en la que ella y otras mujeres usaron kefias palestinas y desplegaron un lienzo que rezaba: "No al feminismo sin antimperialismo”. En un momento de la manifestación, otras feministas comenzaron a proclamar slogans de solidaridad con las mujeres iraníes. Boutelja relata:

"Por nuestra parte, decidimos expresar nuestra solidaridad no hacia las mujeres del tercer mundo, sino hacia las mujeres occidentales. Así, comenzamos a gritar: ¡Solidaridad con las suecas! ¡Solidaridad con las italianas! ¡Solidaridad con las alemanas! ¡Solidaridad con las inglesas! ¡Solidaridad con las francesas! ¡Solidaridad con las norteamericanas! (...)...Lo cual significaba: ¿por qué solamente ustedes, mujeres blancas, tienen el privilegio de la solidaridad? Ustedes también son golpeadas, violadas, ustedes también sufren las violencias masculinas, ustedes también son mal pagadas, despreciadas, sus cuerpos también son instrumentalizados...Les puedo decir que nos miraron como si fuéramos unas extraterrestres...” (Boutelja, 2010, párr.5-6, énfasis mío).

En cuanto a la cuestión del velo, Boutelja critica el racismo islamofóbico de algunos de los argumentos más reiterativos del feminismo 
en favor de la prohibición del velo. Ella nos explica que para muchas de las jóvenes de los suburbios de Paris, usar el velo es una forma de administrar sus relaciones con los hombres “árabes”:

“Estamos obligadas a construir un feminismo paradojal. Lo que significa hacer una crítica radical del sexismo en nuestro medio y en la sociedad y al mismo tiempo, rechazar los discursos racistas y esencialistas que bestializan a los hombres árabes (...) No es como para las francesas que no tienen más que luchar directamente contra sus hombres. Nosotras debemos luchar para que nuestros hermanos y nuestros padres sean rehabilitados (...) [Se trata] de una competencia patriarcal entre hombres, pero una competencia que va a la par con una relación de racismo (...) Hay que pasar por su revalorización [del velo], por su rehumanización (...) dar pruebas de lealtad para ganar nuestra libertad (...) El feminismo ideal no podemos permitírnoslo: es un lujo de blancas! (...) La significación del velo es ésa: el velo dice a los hombres blancos: “no nos tendrán” (...) El velo es un mensaje que dice al hermano: "puedes confiar en mí, yo no te traicionaré..."” (Boutelja, Hamel \& Delphy, 2006: 128-134, énfasis mío).

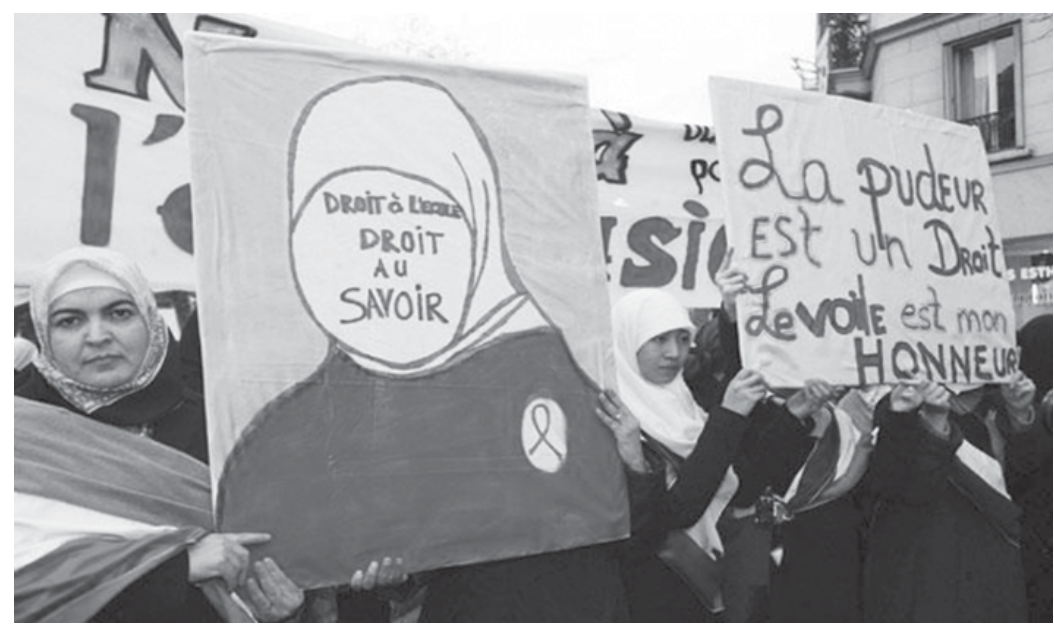

Manifestación en contra la prohibición del velo, Paris 2012.

Frente a este argumento, una de las representantes francesas del feminismo anticolonial, la filósofa Elsa Dorlin, responde:

“La femineidad encarnada por las jóvenes feministas musulmanas militantes es una respuesta presente a la persecución pasada de nuestras madres colonizadas, estigmatizadas como mujeres lascivas, inmorales y sumisas. Sin embargo, es una respuesta que perma- 
nece prisionera en la dialéctica del saber y del poder colonial: "la joven con velo" performatea una femineidad tradicional, virgen, piadosa y efectivamente poderosa (como todas las figuras femeninas heroicas, vírgenes combatientes o amazonas) (...) Hacer acto de lealtad hacia nuestros hombres, dando garantías y rindiendo cuentas de nuestras sexualidades es -guardando las proporciones- ratificar el conjunto de los estereotipos coloniales; es reconocer que como ayer, tenemos la responsabilidad de su persecución ("traidoras”), que somos el punto débil del combate antiracista” (2009:60, énfasis mío).

Sin posibilidad de instalar de manera mimética estos debates en el contexto local, me pregunto si a partir de este clivaje entre el racismo del feminismo y el sexismo del combate antirracista, cabría sugerir una cierta afinidad entre estas historias “difícilmente accesibles al lenguaje”. Si la respuesta es afirmativa: ¿qué silencios, contradicciones o malestares podrían evidenciar la necesidad de un "feminismo mapuche" en Chile?

\section{La pregunta por un "feminismo mapuche"}

Como un primer elemento para la discusión, creo importante problematizar el cómo las imágenes del cuerpo femenino mapuche desnudo hacen emerger, por contraste, al cuerpo femenino “tradicional”. Así es posible evidenciarlo, por ejemplo, a partir del comentario de Pérez \& Retamal (2001) sobre la aparición de la vedette mapuche "Solange Star", cuya foto fue publicada por el diario La Cuarta en 1992. Los autores entienden esta imagen como interpeladora de "la visión clásica sobre la cultura como un todo coherente, que perdura inalterable e insensible a las transformaciones externas” (2001: 82).

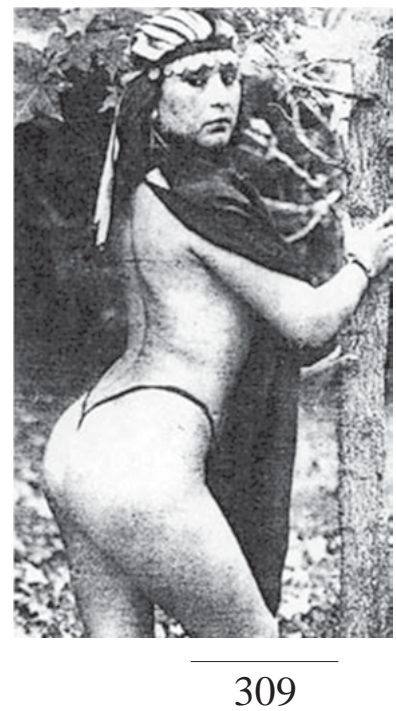

"Solange Star", vedette Mapuche. La Cuarta, 21 de Febrero de 1992 (Pérez \& Retamal, 2001). 


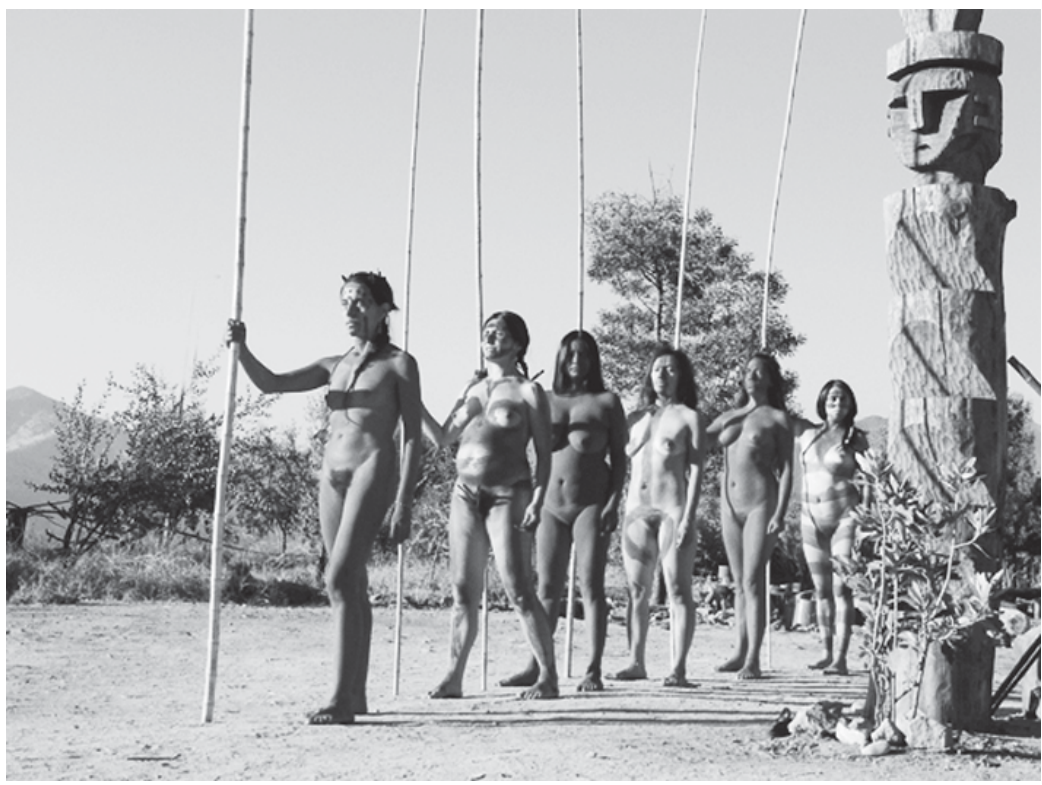

“Malen Weichafe”, 2006 (Proyecto Aillapan, danza drama mapuche)

Esta alusión por contraste al cuerpo femenino como representación nacional de "lo inmutable", también me lleva a pensar en un texto de André Menard en el cual se consigna un mail colectivo que circuló en el año 2006, a propósito de un proyecto teatral llamado "Malen Weichafe" ("Mujeres Guerreras”). Menard señala que en el mail se adjuntaron algunas fotos de mujeres desnudas que aparecían con sus cuerpos pintados y enarbolando lanzas. Escandalizado frente a este espectáculo, el autor del mail titulado «La Sociedad Secreta Reche, al mundo Mapuche», sostenía:

"Ante este insulto hacia nuestra Cultura Mapuche, debemos señalar que desde que tenemos uso de razón nuestra cultura siempre a [sic] llevado ropa y la ropa crea una distinción en lo político, social y espiritual, así nos lo han enseñado nuestros ancestros...De igual forma nunca una Machi se ha mostrado desnuda frente a su Rewe en una ceremonia [La cultura mapuche] no es una cultura machista, ni feminista, cada uno sabe su labor para mantener el equilibrio del hogar, en este universo que se llama Ruka” (citado en Menard, 2009: 16, énfasis mío).

Desde este preámbulo, Menard reflexionará sobre el rol del pudor en la representación de "la raza mapuche”. Después de rastrear uno de los debates atingentes al respecto ${ }^{9}$ a comienzos del siglo $\mathrm{XX}$, el autor concluirá: 
"Más allá de su violento anacronismo, el escándalo de la Sociedad Secreta Reche ante la desnudez de las Malen Weichafe, devela la continuidad secular de una preocupación por la representatividad de la raza, que, pese a sus reformulaciones en términos culturales o étnicos, parece seguir remitiendo al juego de descubrimientos y ocultamientos que en última instancia remiten a las diversas posibilidades (desnudez, pudor, mancilla...) de un cuerpo y su presencia” (Ibid: 37, énfasis mío).

Claudia Zapata (2006) ha sostenido que en la escritura de un gran número de intelectuales mapuche contemporáneos, "la diferencia cultural" es uno de los ejes discursivos claves. Para José Ancán, la reivindicación de esta "diferencia" adquiere muchas veces la forma de un "argumento cosmovisionista” que defenderá una alteridad profunda e irremontable de la tradición, espiritualidad y cosmogonía mapuche. Esta revalorización de la tradición localizada en un pasado incorpóreo, conllevaría un énfasis en el abismo de la diferencia que, paradójicamente, satisfaría de más en más a un público chileno consumidor de exotismo. De esta forma, sostiene Ancán, "la sociedad propia es visualizada en términos de victimización y autoexaltación. Desde un "nosotros" dañado por la historia a uno que puede hablar en igualdad de condiciones, a través de las diferencias culturales insalvables, con la sociedad mayor" (2010: 118).

Menard (2012), por su parte, problematiza la reivindicación de esta “diferencia” a partir de la idea de una "política del reducto", que sería utilizada tanto por el Estado Chileno como por los mismos dirigentes mapuche. La idea de "reducto" remitiría a un capital carismático y guerrero, concentrado de autoctonía e identidad, espiritualmente incodificable, reserva de pureza espiritual de la modernidad y al mismo tiempo, "reducto" como aquello que debe ser preservado en virtud de su vulnerabilidad o escasez.

A partir de todo lo anterior, la pregunta que quisiera plantear alude a las expectativas de género que moldean estas representaciones morales y espirituales de "la raza”. O dicho de manera más concreta: ¿qué representación de "la mujer mapuche legítima" es la enturbiada por los inquietantes cuerpos de "Solange Star" o de las "Malen Weichafe”?, ¿¿cuáles, sus efectos políticos?

Pensando justamente en el carácter sexuado de estas representaciones, Bacigalupo (2010) ha sostenido que en la medida en que el Estado chileno sólo reconoció a los longko como interlocutores políticos y símbolos adecuados de virilidad guerrera, el rol "espiritual y afeminado" de los hombres machi fue rechazado y fue "la mujer machi" la que se transforma en la representante y guardiana de la tradición espiritual mapuche. Es en esta línea que creo habría que interrogar la presentación pública del cuerpo femenino tradicional -vestido de largo negro, cintillo, pañuelo, faja, capa y plata- como legitimador y sostenedor de "la identidad mapuche", tanto en las escenas de lucha como en las escenas de pacto o diálogo con el Estado chileno. 
La pregunta acerca de los mandatos morales de género, puede levantar más de una defensa por parte de hombres y mujeres mapuche. Así lo constataban Patricia Richards y Millaray Painemal, quienes relatan que en el año 2003, al finalizar un congreso titulado "Diversidad cultural: los derechos de las mujeres indígenas”, un joven mapuche llamado Oswaldo realizó una intervención en la que preguntaba si se estaba hablando

“de la cultura Mapuche "real” o de la “actual”. Era importante hacer la distinción -dijo- porque los Mapuche siempre han honrado a las mujeres, como se evidencia en la reverencia por las machi (...) y en el hecho de que en la cosmovisión Mapuche, el hombre y la mujer juntos forman un díada y actúan en equilibrio y complementariedad (...) En su opinión, era la corrupción de la cultura Mapuche por parte de los españoles y chilenos la que había provocado problemas entre las mujeres y los hombres. Era desacertado y equivocado hablar de género porque el género no tiene nada que ver con la cultura Mapuche "real” (...) Además, él había escuchado el rumor de que se estaba gestando un movimiento feminista Mapuche y sentía que esto iba en contra de todo lo que significaba la cultura Mapuche. La organización de las mujeres y el hablar de género, concluyó Oswaldo, sólo servirían para dividir a la gente (...) Aunque algunas en el público pertenecían a las organizaciones de mujeres Mapuche, ninguna se puso de pie para refutar las declaraciones de Oswaldo... [Excepto] Isabel, una profesora Mapuche de una universidad local, [quien] declaró que los académicos que estudian a los Mapuche siempre utilizan conceptos occidentales -tales como género- que no encajan con la realidad Mapuche. "El género no existe para los Mapuche” dijo” (Richards \& Painemal, 2006:1-2, énfasis mío).

En las breves alusiones que he hecho a las luchas de las comunidades negra, chicana y musulmana, es posible apreciar esta misma representación del "feminismo separatista” y debilitador de la unidad del movimiento. Tal como podemos apreciar a través de las palabras de Isabel, esta representación tampoco es algo aislado entre las mujeres mapuche. En esta línea, resulta interesante el texto "Mujer mapuche feminista” de Diva Millapan. Allí, la autora sostiene que "las mujeres dirigentas no tenían espacio para el feminismo, porque debían representar a un pueblo” (2013, párr.9, énfasis mío).

La idea del “feminismo separatista” también emerge en los testimonios de algunas de las mujeres jóvenes que Richards y Painemal pudieron entrevistar en el 2003. Ellas rechazaban el concepto "género" porque "lo asociaban con el feminismo al que consideran anti-hombres” (2006:12). Otra dirigente anónima entrevistada por Painemal, señalaba que "de haber mujeres feministas hay, pero nosotros como mujeres mapuche que nos definamos como feminista, no. El pueblo mapuche involucra a toda la familia, no deja a nadie fuera” (citada en Painemal, 2013, párr.2, énfasis mío).

Si consideramos la apropiación nacional del concepto “género” por parte del SERNAM o el cinismo del discurso del "liderazgo femenino dife- 
rente”, esta desconfianza parece sustentarse. Junto con ello, los estereotipos sobre el feminismo parecen evidenciar la falta de encuentro y de construcción de solidaridades entre las voces críticas del feminismo chileno y las mujeres mapuche.

Ahora bien, esta representación del feminismo como amenaza podría no ser problemática si las vivencias de sexismo al interior de las comunidades mapuche no existieran. Lejos de ello, un primer eje de conflicto se evidencia en las dificultades de las mujeres mapuche para ejercer roles de liderazgo.

Así lo sostiene Painemal: “La aparición, en los últimos años, de organizaciones femeninas mapuche responde, primero, a una falta de espacios al interior de organizaciones mixtas, donde son los hombres quienes tienen la voz en la toma de decisiones” (2008:8, énfasis mío). Lo reafirmaba Millapan: “...estábamos en una jornada y teníamos un dirigente importante invitado acá en Santiago... dice el presidente "porque [sic] las lamgen nos preparan el almuerzo mientras nosotros (los hombres) hacemos la reunión” ¿¿¿qué??? y yo dije “yo me quedo a la reunión... no vine a cocinar... y si mejor cocinamos todos, los hombres también pueden hacerlo”... me miraron con una cara de horror de horror” (2013, párr.10, énfasis mío). La dirigenta Isolda Reuque, por su parte, señala que fue justamente esta situación lo que la llevó a fundar una organización mapuche sólo de mujeres, ya que en las organizaciones mixtas ocupaban "puestos de segunda categoría, secretarias, tesoreras (...) A los hombres en general, los hombres mapuches, les molesta que uno hable. Les interesa que las mujeres hagan las cosas, medio adivinándolas..." (citada en Cuminao, 2009:116, énfasis mío).

Un segundo eje de conflicto del que es posible dar cuenta de manera preliminar, emerge en afinidad con el caso afroamericano ya aludido. Se trata de la cuestión de la violencia en parejas heterosexuales, de la mano de su amenaza colonial: el reforzamiento del estereotipo del hombre mapuche salvaje, alcohólico y machista.

Distintas mujeres mapuche han sostenido que sobre la violencia al interior de las comunidades, es difícil hablar. Así lo enunciaba la misma dirigenta entrevistada por Painemal: “de que hay violencia hay, violencia de una u otra manera, física o verbal, pero como que no se muestra mucho, no se da a conocer” (2013, párr.2). Este silencio también es constatado por Andrea Reuca, ex-vocera de la Coordinadora de Hogares Mapuche: "Las violencias sobre mujeres son numerosas en la comunidad, pero no es un tema tratado” (citada en Mattus, 2009:25). Por su parte, Pilar Collipal, quien para el 2012 llevaba 15 años trabajando en el SERNAM, señala que en general a las mapuche rurales: "el denunciar cuesta mucho...por una no destrucción de su familia, porque en el fondo también [la mujer] sabe que haciendo la denuncia vas a castigar a una persona a la cual quieres y que es parte de tu clan y eso cuesta en el mundo mapuche” (citada en López, 2012). Al respecto, Painemal también llama la atención sobre la declaración del SERNAM publicada por el Diario Austral de Temuco, el 11 de marzo del 
2013: entre el 2011 y el 2012, diecisiete hombres mapuche fueron exculpados de las penas asociadas al maltrato a las mujeres mapuche que eran sus parejas, invocando "la costumbre ancestral que se encuentra presente en el Convenio 169 de la OIT. Esto significó que los agresores sólo pidieran disculpas públicas y se les dejó libre de toda pena” (Painemal, 2013, párr.8) ${ }^{10}$.

Pilar Collipal, Minerva Castañeda Meliñan, Andrea Reuca, Isolda Reuque y Margarita Calfio afirman que fue el colonialismo y "la educación no-Mapuche” los que reforzaron estos patrones. Así por ejemplo, Minerva Castañeda, quien para el 2009 era la encargada del Centro de documentación de la CONADI, señala que -en algunos aspectos- las mujeres mapuches eran más respetadas y protegidas antes: "Por ejemplo el hecho de los derechos reproductivos, el tema del aborto no era un tema punitivo como es ahora en la sociedad chilena (...) Ella era libre de iniciar su vida sexual, tanto la mujer soltera como la mujer viuda” (citada en Mattus, 2009: 18).

Calfio, por su parte, sostiene que no es que en tiempos de libertad no existiera subordinación de las mujeres a los hombres mapuche, sino que esta subordinación "no implicaba desvalorización, ni falta de espacio propio (...) En este nuevo escenario la mujer como medio de intercambio perdió valor social y su papel reproductivo ya no fue apreciado como en tiempos de libertad” (2009:92). Actualmente, sostiene la autora, la pérdida del valor social de las mujeres mapuche se evidencia en algunos testimonios en los que es posible palpar "un sentimiento negativo respecto a la condición de mujer (...) [al] recibir menosprecio y humillación, de hombres acomplejados y ahogados en alcohol” (2012:288, énfasis mío).

Sin embargo, Calfio y Velasco son claras al momento de evaluar las justificaciones en relación a esta situación:

“...el pretexto del respeto a los "usos y costumbres”, la falsa idealización del mito del "buen ecológico indígena”, "la complementariedad” y otras figuras creadas igual por hombres para explicar o justificar la subordinación y las relaciones desiguales. Las mujeres muchas veces ocultan su subordinación para evitar el debilitamiento de los movimientos indígenas” (Calfio \& Velasco, 2005: 5, énfasis mío).

En una línea similar, Isolde Reuque señala sus dudas con respecto al argumento de la complementariedad:
“en términos del “deber ser” de la cultura mapuche se habla de la complementariedad entre el hombre y la mujer, pensamiento que es reforzado en las oraciones de los y las machi, donde está presente la dualidad y la complementariedad. Sin embargo, en la práctica coti- diana muchas veces sucede lo contrario y surge el machismo que paraliza a la mujer” (citada en Cuminao, 2009:117).

Quisiera detenerme en este argumento que me parece reiterativo en 
Chile. Defendida por Oswaldo (según el relato de Richards \& Painemal), esta idea también está presente en las palabras de Andrea Reuca: "el enfoque de género es una contradicción en la cultura mapuche, porque justamente hay un equilibrio natural entre el hombre y la mujer" (citada en Mattus, 2009:19, énfasis mío). O en el deseo de María Isabel Curihuentro, para quien se trataría entonces de "volver a un equilibrio entre hombres, mujeres y naturaleza” (citada en Mattus, 2009:23).

Una primera lectura crítica de esta idea podría entenderla como idealización del pasado y negación defensiva del presente. Aquí, cabría poner en duda la distinción de Oswaldo con respecto a una cultura mapuche "real” y otra "actual”, corrompida. Siguiendo los argumentos de Ancán (2010) y Menard (2009), es importante levantar una pregunta con respecto a la función política actual que cumple la representación de ese pasado como paraíso prístino de armonía espiritual entre hombres y mujeres. Invirtiendo las valoraciones (esta vez en favor del "pueblo mapuche") de una dicotomía históricamente colonialista (puro/impuro), la retórica de la complementariedad arriesga caer en una trampa ya señalada por Fanon (2004): por una suerte de perversión del pensamiento colonial, los efectos subversivos de las modalidades prácticas o discursivas de la emancipación de los colonizados, son neutralizados.

Por otra parte, y siguiendo la lógica de la reflexión de Menard (2009) con respecto al rol que ha cumplido el pudor en la representación de "la raza mapuche”, me pregunto si será posible separar en unidades discursivas discretas lo que los antropólogos/as, misioneros/as, educadores y políticos/as han dicho sobre las/los mapuche de aquello que las/los mapuche han dicho sobre sí mismos/as. Enunciado de otra manera: ¿¿será posible pensar que no existe interacción alguna entre la complementariedad del cosmovisionismo y aquel que ha sido el argumento maestro de la política de género de la modernidad: la naturaleza diferente y complementaria de los sexos?

Este argumento antropológico y "científico" marcó las representaciones modernas del "hombre" y "la mujer" con el signo de la inconmensurabilidad de la diferencia (Laqueur, 1992). La lógica sería la siguiente: la diferencia entre "el hombre" y "la mujer" sería inmedible e irremediable en tanto inscrita en el misterio de sus naturalezas. Por lo mismo y tal como lo afirma Varikas (2006), no sería posible cuestionar la autoridad arbitraria que sostiene la definición misma de la división público-privado: se trataría de una cuestión de "naturaleza”, no de voluntad de dominación. Desde esta perspectiva, lo que es nuevo en la política de género inaugurada en la modernidad no es ni la exclusión ni la incapacidad política de las mujeres, sino que una construcción de "la diferencia" que implica una nueva legitimación de la dominación fundada en la naturaleza. La "diferencia de los sexos" se revela así, no como "la causa, sino como la justificación de la exclusión de género" (2006:104). Así, si es posible pensar en el mutuo modelamiento de los argumentos de "la complementariedad del cosmovisionimo" y de "la naturaleza diferente y complementaria de los 
sexos”, cabría consignar entonces el carácter constitutivamente jerárquico de la complementariedad.

Una segunda lectura al respecto, es la que Richards y Painemal comparten con Mattus, y que señala la reivindicación estratégica de este argumento por parte de las organizaciones de mujeres mapuche. Así se desprende de las palabras de Rosa Rapiman, quien ve "la recuperación de la noción de complementariedad como una manera en que la Casa de la Mujer Mapuche puede trabajar por sus derechos” (citada en Richards y Painemal, 2006: 12). En la misma línea, las mujeres mapuche que hacen parte de ANAMURI, han reclamado la necesidad de un lenguaje propio y de que la organización "tome en serio elementos propios de la cosmovisión Mapuche, como la dualidad y la complementariedad”" (Richards y Painemal, 2006:11).

Charlotte Mattus concluirá, así, que el llamado estratégico de las mujeres mapuche a

"la reconstrucción de valores ancestrales basados en el equilibrio mujer-hombre, les permite justificar su voluntad de valoración de su estatus de mujer en la comunidad. La reclamación de complementariedad es una manera [tanto] de exigir cambios frente al hombre mapuche como de afirmar su cultura original” (2009:23).

Según Mattus, se trataría de una estrategia doble, ya que esta reivindicación se inscribe simultáneamente en la lucha "contra el "colonialismo" del Estado chileno, origen del sexismo y de las discriminaciones que ellas viven actualmente. Esta estrategia les permite también solidarizarse con el movimiento mapuche en general, y hacerse reconocer como participante a la lucha de su pueblo” (Ibid: 23).

Relevando el potencial subversivo de esta consciencia de los riesgos colonialistas del uso acrítico de la palabra "género" (vocablo que no ha sido creado ni ha respondido necesariamente a las necesidades de las mujeres mapuche), el eje problemático de esta estrategia discursiva radicaría a mi parecer- en la necesaria "rendición de cuentas" que implica la “complementariedad” como posición enunciativa. Efectivamente, la reivindicación del pasado incontaminado y la focalización de la responsabilidad de todo el sexismo en el Estado y el patriarcado chileno, parecen responder más a la necesidad de tranquilizar a un "patriarcado desvirilizado" que a la lealtad de las mujeres mapuches con sus propias experiencias.

Junto con ello, el resabio heteronormado del discurso cosmovisionista de "la complementariedad" corre el riesgo de reforzar un modelo normativo de "mujer mapuche legítima” que podría marcar de sospecha las existencias de otra mujeres mapuche.

Quizá por eso la cadencia del yo lírico de Ivone Coñuecar ${ }^{11}$ :

“esta / mi herida patagónica/mi dictadura estos / mis padres y ma- 
dres mi huerfanía (...) yo soy de otras minorías / genéricas / sexuales / étnicas / geográficas (...) me gusta la queja / es la excusa de todo mi abandono / mi huérfana consiste en abandonarme a mí misma / como lo hizo la historia / como lo hizo mi madre / como lo hizo luego mi padre / mis amantes y las calles, nunca me sentí parte de algo / nunca seré parte de algo. Adiabática yo, me quedo" (citada en Acosta 344345, énfasis mío).

Si la exclusión del sexismo no es dicha en primera persona, las experiencias de muchas mujeres mapuche devendrán irreales, dudosas, clandestinas. Quizá es por eso que el vocablo “feminismo” emerge al escuchar las palabras de Calfunao, Millapan, Calfio, Painemal...porque el sujeto del feminismo no es algo previo, sino que el efecto de una lucha. Dicho en palabras de Alejandra Castillo: "la política del feminismo siempre es una política de la definición. La palabra feminismo no alberga en sí misma una forma única de entender la política de mujeres. Es siempre un ejercicio polémico de toma de palabra” (2011:13).

Mi impresión es que los silencios, contradicciones, malestares y "tomas de la palabra” de las mujeres mapuche que aquí he citado, hacen parte de una tradición (chicana, negra, musulmana, latinoamericana), cuyo linaje es feminista. 


\section{Notas}

${ }^{1}$ Una primera versión de este texto fue presentada como ponencia en las "Quintas Jornadas Caribeñistas: Movimientos y escrituras anticoloniales en América Latina y el Caribe”, realizadas en la Facultad de Filosofía y Humanidades de la Universidad de Chile entre los días 27 y 29 de noviembre de 2013.

${ }^{2}$ A lo largo del texto, utilizaré las comillas para señalar el carácter arbitrario e históricamente construido, de categorías y estereotipos raciales.

${ }^{3}$ De aquí en adelante, las traducciones de todas las citas del inglés y del francés, son mías.

${ }^{4}$ En esta última frase, Dorlin homenajea el título de uno de los libros clave del feminismo "negro" escrito por Gloria Hull, Patricia Bell Scott y Barbara Smith en 1982: All the Women are White, all the Blacks are Men, but some of us are Brave.

${ }^{5}$ La expresión "Black Power" fue acuñada en términos políticos por Stokely Carmichael, un dirigente del Student Nonviolent Coordinating Committee (SNCC). Su discurso sobre "el poder negro" fue pronunciado en la Universidad de California en 1966 y llegó a ser el slogan del movimiento negro durante los años 1960s-1970s (Barischpolski, 2010).

${ }^{6} \mathrm{Al}$ respecto, ver especialmente la poesía chicana sobre Malinche (Carmen Tafolla, Adaljiza Sosa Riddel, Helen Silvas, Naomi Quiñonez, etc.) y el trabajo gráfico de artistas como Alex Donis, Alma López, Guadalupe Rodrìguez, Ester Hernández, Yolanda López, etc.

${ }^{7}$ En Francia, la ley del 15 de Marzo de 2004 en Francia prohibió los "signos que manifiesten ostensiblemente la pertenencia a una religión” (Ver: http:// www.legifrance.gouv.fr/affichTexte.do?cidTexte=JORFTEXT000000417977 \&dateTexte=\&categorieLien=id [consultado el 25/11/2013]). Por su parte, la ley del 11 de octubre del 2010 (que entró en vigor en abril del 2011) prohíbe explícitamente "la ocultación del rostro en el espacio público". En términos concretos, se prohíbe el uso del velo integral (niqab y burka) en cualquier espacio público, no sólo en instituciones administrativas, sino que también en la calle (Ver: http://www.legifrance.gouv.fr/ affichTexte.do;jsessionid=37278AD8F24C3E3EFDBB843BE88513B8.tpdjo13v 1 ? cidTexte=JORFTEXT000022911670\&dateTexte $=20130724$ [consultado el 25/11/ 2013]).

8 “ Les Indigènes de la République » es un movimiento que nace en el año 2005, a partir del documento “Appel des Indigènes de la République” que convocó a diferentes organizaciones y líderes de izquierda, sindicalistas, asociaciones y asambleas partidarias del "anticolonialismo post-colonial” que además se consideraran críticas del "antirracismo paternalista". El MIR se transforma en partido a partir del "Congrès constitutif du PIR - Congrès Malcolm X”, realizado en febrero del 2010. (Ver: http://indigenesrepublique.fr/le-p-i-r/que-voulons-nous/ [consultado el 25/11/2013]).

${ }^{9}$ Menard rastreará el debate entablado entre el profesor normalista Tomás Guevara y el misionero anglicano Charles Sadleir, a propósito de ésta y otras cuestiones. Esta polémica evidenciará el carácter generizado de las representaciones de "la raza mapuche" 
en disputa: Guevara fundamentará la necesidad de la chilenización y del mestizaje al constatar algunas de las características de la "psicología del pueblo araucano", como su tendencia al alcoholismo y la impudicia de sus mujeres. Sadleir contestará que sería injusto juzgar a toda una raza a partir de su "bajo pueblo”. Así, el pastor anglicano apelará a una representación encarnada por una aristocracia mapuche vestida de terno y corbata: “viril, moral y pura” (Menard, 2009:26).

${ }^{10} \mathrm{Al}$ respecto, es importante señalar que el partido mapuche Wallmapuwen publicó una declaración de rechazo a este "uso de mala fe del convenio 169", denunciando también "la intencionalidad política de mal utilizar un instrumento jurídico tan relevante para el pueblo mapuche” (Mapuexpress.net, 2013).

${ }^{11}$ Joven poeta disidente sexual. Actualmente, Coñuecar escribe su novela CoyhaiQueeR (Ver: http://iconuecar.blogspot.com/ [consultado el 5 de octubre de 2013]) 


\section{Bibliografía}

Acosta, D. (2010), “Adiabática” en Aisthesis N 47, p.343-345.

Ancán, J. (2010), “Negritud y cosmovisionismo mapuche frente al poder (neo) colonial. Apuntes preliminares para una reflexión (auto) crítica” en E. Oliva, L. Stecher \& C. Zapata (eds). Aimé Césaire desde América Latina. Diálogos con el poeta de la negritud. Ediciones Facultad de Filosofía y Humanidades, Universidad de Chile, Santiago, p. 201-229.

Barros, P. (2006), Pliego de peticiones. Disponible en: www.mujeresconbachelet.cl [consultado el 18 de mayo de 2007].

Barischpolski, B. (2010), “Black power. Poder negro” en Las tesinas de Belgrano, N414. Disponible en: http://webcache.googleusercontent.com/ search?q=cache:jbJZGwb2DyEJ:www.ub.edu.ar/investigaciones/tesinas/ 414_barischpolski.pdf $+\& \mathrm{~cd}=2 \& \mathrm{hl}=\mathrm{es} \& \mathrm{ct}=\mathrm{clnk} \& g \mathrm{l}=\mathrm{cl}$ [consultado el 5 de diciembre de 2013].

Bidaseca, K. (2010), Perturbando el texto colonial. Los estudios (pos) coloniales en América Latina. Editorial SB, Buenos Aires.

Bidaseca, K. (2011), “Mujeres blancas buscando salvar a las mujeres color café de los hombres color café. O reflexiones sobre desigualdad y colonialismo jurídico desde el feminismo poscolonial” en Feminismo y poscolonialidad. Descolonizando el feminismo desde y en América Latina. Ediciones Godot, Buenos Aires, p. 95-118.

Boutelja, H. (2010), ¿Es el feminismo universal?. Intervención realizada en el IV Congreso Internacional de Feminismo Islámico, Madrid, 21-24 de octubre. Disponible en: http://www.redmusulmanas.com/houria-bouteldjaportavoz-del-pir-en-el-el-iv-congreso-internacional-de-feminismo-islamico [consultado el 30 agosto de 2013]

Boutelja, H., Hamel, Ch. \& Delphy Ch. (2006), “On vous a tant aimé-e-s! Entretien avec Houria Boutelja”, en Nouvelles Questions Féministes, Vol. $25, \mathrm{~N}^{\circ} 1$, p. $122-135$.

Calfio, M. \& Velasco, L. (2005), Mujeres indígenas en América Latina: ¿brechas de género o de etnia?. Ponencia realizada en el Seminario internacional pueblos indígenas y afrodescendientes de América Latina y el Caribe: relevancia y pertinencia de información sociodemográfica para políticas y programas, CEPAL, Santiago, 27-29 de abril.

Calfio, M. (2009), “Mujeres mapuche, voces y acciones en momentos de la historia” en A. Pequeño (comp.) Participación y políticas de mujeres indígenas en contextos latinoamericanos recientes. Ediciones FLACSO-Ecuador, Quito, p.91-109. 
Idem (2012), “Peküyen” en Ta iñ fijke xipa rakiwuameluwün. Historia, colonialismo y resistencia desde el país Mapuche. Ediciones Comunidad de Historia Mapuche, Temuco, p.285-301.

Calfunao, J. (2011), “Comunicado nacional e internacional ». Disponible en: http://calfunaopaillalef.blogspot.com/search?q=bachelet [consultado el 5 abril de 2013].

Castillo, A. (2011), “El feminismo no es un humanismo” en Coordinadora Universitaria por la Disidencia Sexual (eds.) Por un feminismo sin mujeres. Territorios Sexuales Ediciones, Santiago, p. 13-21.

Crenshaw, K. (2005), “Cartographies des marges : interseccionalité, politique de l'identité et violences contre les femmes de couleur”, en Les Cahiers du Genre, N ${ }^{0} 39$, p. 51-82.

Crispi, P. (2006), Nuevos tratos y respetos. Disponible en: www.mujeresconbachelet.cl [consultado el 18 de mayo de 2007].

Cuminao, C. (2009), "Mujeres mapuche: voces y escritura de un posible feminismo indígena” en A. Pequeño (comp.) Participación y políticas de mujeres indígenas en contextos latinoamericanos recientes. Ediciones FLACSO-Ecuador, Quito, p.111-124.

Davis, A. (2004), "El racismo en el movimiento sufragista de las mujeres”, en Mujeres, raza y clase. Ediciones Akal, Madrid, p.77-91.

Dorlin, E. (2005), “De l'usage épistémologique et politique des catégories de sexe et de race dans les études sur le genre”, en Les Cahiers du Genre, N ${ }^{\circ}$ 39, p. 85-107.

Idem (2007), "Performe ton genre, performe ta race !: Re-penser l'articulation entre sexisme et racisme à l’ère de la postcolonie”. Les soirées de Sophia [en línea], p.49-66. Disponible sur : http://www.sophia.be/app/webroot/files/ 2006-2007\%20- \%20_Performe\%20ton\%20genre,\%20performe \%20ta\%20race_\%20-\%20Elsa\%20Dorlin.pdf [consultado el 7 de noviembre de 2009].

Fanon, F. (2004), Les damnés de la terre. La Découverte, Paris.

Laqueur, T. (1992), La fabrique du sexe. Essai sur le corps et le genre en Occident. Gallimard, Paris.

López, S. (2012), “Violencia y mujeres mapuche”, en Feministas Tramando, 2012. Disponible en: http://feministastramando.wordpress.com/2012/ 10/24/violencia-y-mujeres-mapuche/ [consultado el 12 de abril de 2013].

Mattus, Ch. (2009), Los derechos de las mujeres mapuche en Chile. Documento de trabajo Instituto de Estudios Políticos de Grenoble-Universidad 
Pierre Mendès France. Disponible en: http://www.observatorio.cl/sites/ default/files/biblioteca/los_derechos_de_las_mujeres_mapuche_en _chile11.pdf [consultado el 4 de noviembre de 2013].

Menard, A. (2009), "Pudor y representación. La raza mapuche, la desnudez y el disfraz” en Aisthesis, N46, p.15-38.

Idem (2012), "Políticas del reducto (mapuche)” en Actuel Marx/Intervenciones $N^{\circ}$ 12. LOM Ediciones, Santiago, p. 241-253.

Millapan, D. (2012), Mujer mapuche feminista. Disponible en: http:// divamillapan.bligoo.cl/mujer-mapuche-feminista [13 enero 2013].

Painemal, M. (2008), “El velo de la mujer mapuche” en AZDomingo. Mujeres de la tierra, 9 de marzo. Disponible en: http://www.mapuche.info/ azkin/az_domingo14.pdf [consultado el 15 de noviembre de 2013].

Idem (2013), Mujeres mapuche y el aporte del feminismo en la lucha contra la violencia de género. Disponible en: http://kaosenlared.net/america-latina/item/55844-mujeres-mapuche-y-el-aporte-del-feminismo-en-la-luchacontra-la-violencia-de-g\%C3\%A9nero.html [consultado el 4 de junio de 2013].

Paredes, A. (2006), “Parias” en S. Falabella et al. (eds.) Hilando en la memoria. 7 mujeres mapuche. Editorial Cuarto Propio, Santiago, p. 85-94.

Pérez, F. \& Retamal, G. (2001), “El cuerpo como soporte simbólico: el caso de Solange Star”, en Revista Chilena de Antropología Visual, N¹, p.80-84.

Pratt, M. L. (1993), "Yo soy la Malinche: chicana writers and the poetics of ethnonationalism”, en Callaloo, Vol. 16, N4, p. 859-873.

Red de mujeres mapuche de Chile (2013), “Declaración de la Red de Mujeres Mapuche de Chile”, 8 de marzo. Disponible en: http:// redeibchile.blogspot.com/2013/03/declaracion-de-la-red-de-mujeres.html [5 abril 2013]

Richards, P. \& Painemal, M. (2006), Transnacionalización, derechos humanos y mujeres mapuche. Ponencia presentada en el V Congreso de la Red Latinoamericana de Antropología Jurídica (RELAJU). Oaxtepec, México, 16-20 de octubre. Disponible en: http://www.ciesas.edu.mx/proyectos/relaju/ cd_relaju/Ponencias/Mesa\%20Chenaut-Barrag\%C3\% A 1 n/ PainemalMillarayRichardsPatricia.pdf [consultado el 8 de noviembre de 2013]

Truth, S. (1851), Ain't I A Woman?. Discurso pronunciado en Women's Rights Convention, Ohio, 29 de mayo. Disponible en: http:// womenshistory.about.com/od/sojournertruth/a/aint_i_a_woman.htm [consultado el 13 diciembre de 2012]. 
Varikas, E. (2006), Penser le sexe et le genre. Presses Universitaires de France, Paris.

Varikas, E. (2007), Les rebuts du monde. Stock, Paris.

Vera, A. (2009), “Una crítica feminista a la madre pública postdictatorial: los discursos de género en la campaña presidencial de Michelle Bachelet”, en Revista Nomadías, N¹0. Editorial Cuarto Propio, Santiago, p.111-129.

Idem (2012), La supériorité morale des femmes au Chili : un discours civilisateur. Tesis Doctoral. Escuela Doctoral Pratiques et théories du sens : Université Paris VIII.

Wallmapuwen (2013), Declaración pública. Disponible en: http:// www.mapuexpress.net/content/news/print.php?id=10024 [consultado el 18 de noviembre de 2013].

Wilde, A. (1999), “Irrupciones de la memoria: la política expresiva en la transición a la democracia en Chile”, en Anne Pérotin-Dumon (dir.). Historizar el pasado vivo en América Latina. Disponible en: http:// historizarelpasadovivo.cl/downloads/wilde.pdf [consultado el 3 de octubre de 2007]

Zapata, C. (2006), “Identidad, nación y territorio en la escritura de los intelectuales mapuche” en Revista mexicana de sociología, Vol. 68, No. 3, p. 467-509.

Recibido: 18.12.2013

Aceptado: 15.07.2014 